\title{
0
}

OLHARES

REVISTA DO DEPARTAMENTO DE EDUCAÇÄO- UNIFESP

\section{O ESTÁGIO COMO POSSIBILIDADE DE PESQUISA NA LICENCIATURA EM PEDAGOGIA E A TEORIA DOS CAMPOS CONCEITUAIS DE GÉRARD VERGNAUD}

\author{
PASANTÍA COMO POSIBILIDAD DE INVESTIGACIÓN EN LA \\ LICENCIATURA EN PEDAGOGÍA Y LA TEORÍA DE LOS CAMPOS \\ CONCEPTUALES DE GÉRARD VERGNAUD
}

\author{
THE INTERNSHIP AS A RESEARCH POSSIBILITY IN PEDAGOGY \\ UNDERGRADUATAND GÉRARD VERGNAUD'S CONCEPTUAL FIELDS \\ THEORY
}

\author{
Jéssica de Godoi Baima \\ Universidade Federal de São Carlos - UFSCar \\ jessica.gbaima@gmail.com \\ Klinger Teodoro Ciríaco \\ Universidade Federal de São Carlos - UFSCar \\ klinger.ciriaco@ufscar.br
}

\begin{abstract}
Resumo: Busca-se, no presente artigo, compartilhar encaminhamentos e resultados de uma investigação que descreve/analisa o estágio obrigatório como possibilidade de pesquisa, a partir da experiência da primeira autora no contexto da licenciatura em Pedagogia, na Universidade Federal de São Carlos - UFSCar. A produção dos dados em questão teve como mote reflexões decorrentes de uma intervenção, sob a abordagem qualitativa em educação, no $3^{\circ}$ ano do Ensino Fundamental em que a Teoria dos Campos Conceituais de Gérard Vergnaud foi o referencial teórico-metodológico para o trabalho com a resolução de problemas em uma escola pública estadual. Dada a realidade vivenciada, foi possível concluir que as vivências do estágio desempenham papel fundamental para a formação de professores, uma vez que estas oportunizaram, no caso pesquisado, processos de ressignificação do conhecimento "de" e "sobre" a Educação Matemática, bem como para conhecer a realidade do trabalho na escola e para percursos de identidade profissional de uma futura professora que ensinará Matemática.
\end{abstract}

Palavras-chave: Estágio. Formação de Professores. Teoria dos Campos Conceituais

Resumen: Este artículo busca compartir referencias y resultados de una investigación que describe/analiza la pasantía obligatoria como una posibilidad de investigación, basada en la experiencia de la primera autora en el contexto de una licenciatura en Pedagogía, en la Universidad Federal de San Carlos - UFSCar. La producción de los datos en cuestión tuvo como tema reflexiones surgidas de una intervención, bajo el enfoque cualitativo en educación, en el 3er grado, de la educación básica escolar, en que la Teoría de los Campos Conceptuales de Gérard Vergnaud fue el marco teórico-metodológico para trabajar con la resolución de problemas en una escuela pública estatal. Dada la realidad vivida, se pudo concluir que las experiencias de pasantías desarrollan un rol fundamental en la formación de los profesores, ya que brindaron oportunidades, en el caso investigado, para procesos de resignificación del conocimiento "de" y "sobre" la Educación Matemática, así como para conocer la realidad del trabajo en la escuela y para caminos de identidad profesional de una futura profesora que enseñará Matemáticas. 
Palabras clave: Pasantía. Formación de Profesores. Teoría de los Campos Conceptuales.

Abstract: In this article, we seek to share the directions and results of an investigation that describes/analyzes the mandatory internship as a research possibility, from the experience of the first author in the context of the undergraduate degree in Pedagogy, at the Federal University of São Carlos - UFSCar. The production of the data in question was based on reflections arising from an intervention, under the qualitative approach in education, in the third year of elementary school in which the Conceptual Fields Theory of Gérard Vergnaud was the theoretical and methodological reference for the work with problem solving in a state public school. Given the reality experienced, it was possible to conclude that the internship experiences play a fundamental role in teacher education, since they have provided, in the case researched, processes of re-signification of the knowledge "of" and "about" Mathematics Education, as well as to know the reality of the work in the school and for paths of professional identity of a future teacher who will teach Mathematics.

Keywords: Internship. Teacher Training. Conceptual Fields Theory

\title{
Introdução
}

\begin{abstract}
Não será a educação, e muito menos a formação docente, as únicas capazes de transformar a sociedade. A transformação da sociedade - não aquela para manter as mesmas estruturas que alimentam as desigualdades sociais e econômicas - em direção a uma sociedade mais justa, mais humana e mais igualitária, não pode, porém, abdicar do importante papel da educação e da formação docente (DINIZ-PEREIRA, 2007, p. 84).
\end{abstract}

Vivenciamos, no tempo presente ${ }^{1}$, um momento histórico, social, político, econômico e educacional crítico em nosso país e no mundo. A escrita do presente artigo não pode eximirse de um posicionamento frente ao golpe que temos, infelizmente, presenciado quanto ao papel da Universidade pública e do ambiente formativo que esta representa, bem como aos avanços das políticas de ações afirmativas, acesso e permanência ao Ensino Superior que testemunhamos, especialmente no governo Lula e Dilma, do qual somos fruto e parte integrante. Neste contexto, os cursos de licenciatura expandiram-se, significativamente, a partir do Programa de Apoio a Planos de Reestruturação e Expansão das Universidades Federais (REUNI), implementado pelo Decreto 6.096, de 24 de Abril de 2007, que contribui para a chegada dos campi universitários em regiões distintas do Brasil, como ainda para ampliar vagas em instituições com a abertura de novos cursos, como foi o caso de nossa instituição com a oferta da licenciatura em Pedagogia no período noturno.

Dito isso, contextualização fundamental para situarmos o período em que estamos, é importante destacar que resultados de pesquisas que nos antecedem (PIMENTA, 2001; MELLO; LINDNER, 2012) destacam que a dinâmica formativa de grande parte dos estágios se reduz ao exercício de observação dos professores, com supervisão escassa e relatos de

\footnotetext{
${ }^{1}$ Em 2021, em decorrência da posse de um candidato de extrema direita à Presidência da República em $1^{\circ}$ de Janeiro de 2019.
} 
experiências deficientes de análise crítica em relação às bases teóricas, muitas vezes com relatórios meramente descritivos da rotina das salas de aulas sem reflexões consistentes acerca dos processos formativos e das possibilidades que estes anunciam para a constituição da identidade do professor. Além disso, na nossa interpretação, parece existir uma tendência em ressaltar e julgar as "falhas" dos docentes e das escolas, com assertivas que pouco contribuem para a formação dos futuros pedagogos, situação que acaba por contribuir para distanciar, ainda mais, a Universidade das instituições de ensino.

De acordo com a literatura especializada na temática (GONÇALVES; PIMENTA, 1990; PIMENTA; LIMA, 2006), o objetivo do estágio é de possibilitar proximidade com a realidade na qual será inserido o futuro profissional. Nesta compreensão, o estágio, então, se define como um caminho para a reflexão a partir da realidade e essa aproximação necessita de envolvimento e intencionalidade, o que exigirá do professor em formação inicial esforços para apropriação de referenciais teóricos, metodológicos e conceituais das atividades que se materializam no contato com a escola.

Compreendemos o estágio como um espaço-tempo de aprendizagem da docência, desde que este seja mediado e situado com perspectivas de apropriação de referenciais teóricos, reflexão-ação-reflexão das práticas de intervenção pedagógica, o que acreditamos ter ocorrido na proposta que será aqui relatada, visto que este estágio, em específico, não se deu apenas no âmbito das observações, mas oportunizou o contato e experiências para com o fazer docente mediadas pela pesquisa, o que segundo Pimenta (2001) é essencial no contexto do estágio.

Pimenta e Lima (2006) defendem que a pesquisa no estágio pode ser uma estratégia e uma possibilidade de formação como futuro(a) docente, além de oportunizar o desenvolvimento da relação entre os professores da escola com os estagiários. Este método - utilizar o estágio como pesquisa -, permite aprimorar habilidades de pesquisadores a partir das vivências "na" e "com" a escola, problematizando e analisando-as, inclusive por meio do desenvolvimento de projetos (PIMENTA; LIMA, 2006), como o caso que descreveremos neste artigo.

Em relação ao modo de organização do estágio na Universidade Federal de São Carlos - UFSCar, contexto em que nossa experiência transcorreu, cumpre salientar que este componente curricular consiste na inserção dos futuros pedagogos no cotidiano dos anos iniciais do Ensino Fundamental em escolas públicas municipais e/ou estaduais, com carga horária mínima de 60 horas, sendo 48 horas de observação e 12 horas de regência de classe, ou seja, espaço-tempo em que o futuro professor assume a turma e passa a lecionar determinados conteúdos curriculares. Durante esse período, podemos comparar o que vemos 
na teoria e observamos na prática, possibilitando um aprendizado acerca da conduta docente e, principalmente, o que podemos aprender com ela.

A aproximação com a Educação Matemática deu-se com base na possibilidade de constituir referenciais teórico-metodológicos para intervenção, em uma turma de $3^{\circ}$ ano do Ensino Fundamental de uma escola pública local, a qual teve como mote o trabalho com a resolução de problemas com as crianças, momento em que a futura professora (primeira autora) implementou na sala de aula uma sequência didática planejada sob a Teoria dos Campos Conceituais (VERGNAUD, 1990).

Com o compartilhar deste paper, intencionamos destacar aspectos do papel do estágio na formação de professores que ensinarão Matemática, especificamente referimonos à licenciatura em Pedagogia. Relatamos encaminhamentos e resultados de um estudo que toma como objeto de análise as experiências vivenciadas na disciplina "Prática de Ensino e Estágio Docente nos Anos Iniciais do Ensino Fundamental", a qual fora ofertada no $7^{\circ}$ período do curso na UFSCar, durante o primeiro semestre letivo de 2019, sob responsabilidade do segundo aturo, o qual foram o professor formador/orientador de estágio.

\section{O estágio como possibilidade de pesquisa na formação de professores que ensinam Matemática e a Teoria dos Campos Conceituais}

Carvalho (2012), em um estudo sobre o estágio na licenciatura em Matemática com destaques para os anos iniciais, afirma que a comunidade acadêmica e demais agentes educacionais imprimem esforços consideráveis para tentar superar os desafios colocados a esse momento, isso porque "[...] teoria e prática são indissociáveis, uma é indispensável à outra em um processo contínuo de construção do conhecimento" (p. 13).

De acordo com Pimenta e Lima (2006), o estágio geralmente é visto como a parte prática dos cursos em contraposição à teoria. Isso pode ser observado quando estudantes recém-formados dizem que a profissão se aprende "na prática" e/ou que "na prática a teoria é outra". As autoras argumentam que os currículos de formação se constituem em um amontoado de disciplinas isoladas entre si e escassas de nexo com a realidade que as originou. "Assim, sequer pode-se denominá-las teorias, pois constituem apenas saberes disciplinares, em cursos de formação que, em geral, estão completamente desvinculados do campo de atuação profissional dos futuros formando" (PIMENTA; LIMA, 2006, p. 6, destaques das autoras).

Pimenta e Lima (2019, p. 10) argumentam também que "[...] o professor é um profissional crítico-reflexivo e pesquisador de sua práxis e da práxis educativa que realiza na 
escola em que atua". Além disso, este profissional possui também forte formação teórica, compromisso e sensibilidade social e humana a fim de auxiliar na superação de desigualdades educacionais. Essa visão se destaca no meio acadêmico de ensino e pesquisa das instituições públicas (PIMENTA; LIMA, 2019).

Muitas vezes os coordenadores, professores e alunos enxergam o estágio como apenas uma observação, participação e, em alguns casos, como momento de uma regência na sala de aula, logo faz-se preciso analisar até que ponto a escola se torna um ambiente de investigação, sistematização e construção de conhecimentos por meio de reflexões (PIMENTA; LIMA, 2019).

O estágio como ambiente de pesquisa, "[...] além de contribuir para a construção da identidade docente, amplia e aprofunda o conhecimento pedagógico e da práxis educativa docente, especialmente quando se vincula às escolas públicas" (PIMENTA; LIMA, 2019, p. 10).

Acerca dos conteúdos específicos, Pimenta e Fusari (apud GOMES; PIMENTA, 2019), constataram em sua pesquisa - um universo de 144 cursos de Pedagogia pesquisados - que menos de $32 \%$ da carga horária total de disciplinas são destinadas aos conteúdos curriculares e suas metodologias de ensino. Ou seja, é evidente a insuficiência ao considerarmos a complexidade de atuar no ensino básico como professores polivalentes.

Considerando a importância de favorecer o lugar da prática pedagógica nos cursos de licenciatura, vemos o estágio como um momento de grande valor neste processo formativo, desde que bem fundamentado, estruturado e orientado. Como esta disciplina compõe o currículo do curso, o momento do estágio dispõe de um espaço-tempo na Universidade e nas instituições escolares, proporcionando não apenas uma mobilidade entre os espaços físicos, mas também, entre as ideias, concepções, vivências e desafios experienciados nos dois ambientes, o que pode favorecer a construção de aprendizagens significativas.

A proposta de ter o estágio nos anos iniciais como possibilidade de pesquisa em Educação Matemática ainda encontra respaldo no fato de que este espaço pode constituir tempo de desenvolver ações que poderão fazer a diferença na formação, isso porque "[...] conhecer um pouco a dinâmica e a Matemática nos anos iniciais pode favorecer o trabalho deste professor" (CARVALHO, 2012, p. 101-102).

Esse estágio pressupõe outra postura diante do conhecimento, que passe a considerálo não mais como verdade capaz de explicar toda e qualquer situação observada [...]. Supõe que se busque novo conhecimento na relação entre as explicações existentes e os dados novos que a realidade impõe e que são percebidas na postura investigativa (PIMENTA; LIMA, 2006, p.14-15). 
Neste sentido, defendemos o posicionamento de que o estágio pode cumprir um papel importante na articulação e mobilização de conhecimentos ligados às disciplinas de conteúdos e metodologias como, por exemplo, a de Matemática. Isso porque o futuro professor poderá ter a oportunidade, na licenciatura em Pedagogia, de ir além da carga horária-base destinada para este campo do conhecimento, especificamente sobre os fundamentos e metodologias do ensino de Matemática, estudos afirmam concentrarem-se entre 60 e 85 horas, bem como que não conseguem, dado pouco tempo, trabalhar conhecimentos específicos da matéria de ensino (CURI, 2004; GATTI; BARRETO, 2009), motivo que reforça a tese de que ter o estágio como pesquisa em Educação Matemática pode fortalecer aspectos da formação em relação aos conteúdos, especialmente aqui para a Teoria dos Campos Conceituais (TCC).

Seguindo essa linha de raciocínio, podemos compreender a necessidade de se ter, em um curso de licenciatura voltado à formação docente nos primeiros anos, um espaçotempo dedicado aos conteúdos e metodologias que contribua para a aquisição dos conhecimentos pedagógicos, específicos e curriculares, como também para a ampliação do repertório de trabalho docente, o que sabemos ser ainda um desafio. Ou seja, uma formação voltada ao desenvolvimento profissional que prepare o estudante para o domínio de conteúdos e estratégias de possibilitem maior aprendizagem das crianças em ambientes de investigação matemática. No caso da primeira autora deste texto, utilizou-se das práticas do estágio obrigatório no Ensino Fundamental para aproximar-se do ensino da Matemática escolar, uma vez que a disciplina responsável por tal área é ofertada em apenas uma disciplina de um semestre no curso de licenciatura em Pedagogia da Universidade Federal de São Carlos - UFSCar - em uma carga horária que consideramos mínima (60 horas), tentamos recorrer à outros espaços como sendo também formativos e, portanto, catalisadores da aprendizagem docente.

De acordo com Fiorentini et al. (2002), estudos acerca da formação inicial dos professores indicam a necessidade de ampliação de carga didática de disciplinas de prática de ensino e estágio supervisionado e sua distribuição ao longo do curso. Além disso, sobre a formação inicial do professor que ensina Matemática na Educação Infantil e anos iniciais do Ensino Fundamental, os estudos apontam que os cursos, muitas vezes, apresentam escassez de formação didático-matemática (FIORENTINI et al., 2002).

$\mathrm{Na}$ contemporaneidade, a abordagem conceitual dos conteúdos no campo da Educação Matemática conta com diversos métodos e tendências. Uma delas é o ensino por meio da resolução de problemas que, de acordo com Faxina (2017), se baseia na ideia de que os alunos necessitam utilizar seus conhecimentos prévios para resolver os problemas e, 
durante esse processo, um novo conhecimento é construído. Sendo assim, é preciso criar estratégias, autonomia e interpretação, oportunizando a descoberta de conceitos e princípios matemáticos.

Ainda, de acordo com os documentos oficiais e autores da área, destaca-se a necessidade de partir da "Resolução de Problemas" para uma abordagem contextualizada do conhecimento matemático. Logo, resolver problemas é uma ação humana e, portanto, uma atividade permanente desde a mais tenra idade. De acordo com George Polya (1997, p. 1-2), resolver um problema é:

[...] encontrar os meios desconhecidos para um fim nitidamente imaginado. [...] é encontrar um caminho onde nenhum outro é conhecido de antemão, encontrar um caminho a partir de uma dificuldade, encontrar um caminho que contorne um obstáculo, para alcançar um fim desejado, mas não alcançável imediatamente, por meios adequados. Resolver problemas é a realização específica da inteligência, e a inteligência é o dom específico do homem. [...] Podemos caracterizar o homem como o "animal que resolve problemas"; seus dias são preenchidos com aspirações não imediatamente alcançáveis.

Além disso, Polya inclui quatro etapas para a resolução de problemas: 1) Compreender o problema: identificar os dados, o objetivo e as condições apresentadas; 2) Elaborar um plano: saber quais cálculos ou estratégias pode-se utilizar para chegar ao resultado; 3) Executar o plano: efetuar o plano elaborado até chegar à solução e, se chegar a um impasse, voltar à planificação; e 4) Verificar os resultados: revisar criticamente o trabalho realizado.

Estas etapas auxiliam o aluno a estruturar o processo de resolução de um problema, além de colocar questionamentos à si próprio para organizar seu pensamento de modo sistemático e eficaz. Assim, ao professor cabe orientar e mediar o trabalho do estudante, sugerindo problemas apropriados para a idade cognitiva, permitindo a utilização e reflexão dos conhecimentos prévios.

É importante salientar que esta prática não é aleatória. É necessário "[...] reconhecer a diversidade de estruturas de problemas, analisar as operações envolvidas e as operações de pensamento necessárias para resolver cada classe de problemas" (VERGNAUD, 1982, p. 6). Portanto, para cada classe de problemas, as dificuldades e procedimentos variam, além da estrutura dos problemas se configurarem diferenciadamente de acordo com cada classe de problema.

Sobre os conceitos matemáticos, os quais podem ser amparados com uma perspectiva de trabalho no campo da resolução de problemas, buscamos amparo, para constituir o referencial teórico, na Teoria dos Campos Conceituais (TCC) de Vergnaud (1990), que mesmo não se tratando de uma teoria didática, oferece uma estrutura à aprendizagem. 
A TCC é "[...] uma teoria psicológica do conceito, ou melhor, da conceitualização do real, que permite situar e estudar as filiações e rupturas entre conhecimentos, do ponto de vista do seu conteúdo conceitual" (VERGNAUD, 1990, p. 1), ou seja, seu intuito é repensar as condições de aprendizagem conceitual, possibilitando a maior compreensão pela criança.

Este autor francês foi um psicólogo pertencente a tradição de Piaget que procurou investigar o sujeito do conhecimento em reposta à uma situação de ensino. Para ele, o conhecimento está organizado em campos conceituais, cujo domínio por parte do aprendiz acontece ao longo do tempo e por meio da experiência. A TCC surgiu na década de 1980, não é específica da Matemática, apesar de ter sido elaborada para explicar o processo de conceitualização progressiva das estruturas aditivas, multiplicativas, das relações númeroespaço e da Álgebra.

Nos pressupostos que respaldam suas ações, um campo conceitual é "[...] um conjunto informal e heterogêneo de problemas, situações, conceitos, relações, conteúdos e operações de pensamento, conectados uns aos outros e, provavelmente, interligados durante o processo de aquisição" (VERGNAUD, 1982, p. 40).

De acordo com Magina (2005), ao propor estudar um campo conceitual ao invés de um conceito, Vergnaud afirma que, em uma situação-problema, nunca um conceito aparece isolado. Isso significa que existe um conjunto de situações que, para serem dominados, exigem variedade de conceitos, procedimentos e representações simbólicas.

Acerca das tarefas e suas competências, Magina (2005, p. 5) cita que podem ser avaliadas por três aspectos:

(a) análise do acerto e erro, sendo considerado competente aquele que acerta; (b) análise do tipo de estratégia utilizada, podendo alguém ser mais competente que outro, porque sua resolução foi mais econômica ou mais rápida, ou ainda, mais elegante; e (c) análise da capacidade de escolher o melhor método para resolver um problema dentro de uma situação particular.

Assim, ao acertar, é proposto que o professor tente compreender quais foram as estratégias utilizadas pelo aluno para realizar a tarefa. Quanto ao erro, somente a análise possibilitará conhecer as dificuldades enfrentadas pelos alunos e os caminhos para saná-las.

Desta forma, ensinar pressupõe um claro entendimento das atuais competências e concepções do aluno, de suas competências quando ele era mais jovem e das competências que ele precisará ter quando for mais velho. Esta é uma conseqüência direta da Teoria dos Campos Conceituais - herança do passado e preparação para o futuro (MAGINA, 2005, p. 5).

Vergnaud (1990, p. 9) define o "Campo Conceitual das Estruturas Aditivas" como "[...] o conjunto das situações, cujo tratamento implica uma ou várias adições ou subtrações ou uma combinação destas operações, e também como o conjunto dos conceitos, teoremas e 
representações simbólicas que permitem analisar tais situações como tarefas matemáticas". Sobre o "Campo Conceitual das Estruturas Multiplicativas", podemos compreendê-lo como "[...] conjunto de situações que requerem para a sua resolução uma ou mais multiplicações ou divisões ou ainda uma combinação dessas operações e, o conjunto de conceitos e teoremas que permitem analisar matematicamente tais situações" (JESNKE, 2011, p. 46).

Vergnaud (2014) identificou algumas relações de base ao classificar os problemas de adição e subtração da aritmética elementar. Essas situações podem ser classificadas como:

\begin{abstract}
- Composição: nessa classe é possível relacionar parte-todo. Por exemplo, "Num tanque havia 6 peixes vermelhos e 7 peixes amarelos. Quantos peixes havia no tanque?"; - Transformação: nessa classe é possível relacionar estado inicial, uma transformação que leva a um estado final. Por exemplo, "Maria tinha 9 figurinhas e ganhou 4 figurinhas de seu pai. Quantas figurinhas Maria têm agora?"; - Comparação: nessa classe é possível relacionar duas partes comparando-as, tendo sempre duas partes as quais são denominadas referente e referido e uma relação. Por exemplo, "Ana tem 8 anos e Carlos tem 2 anos a mais que ela. Quantos anos têm Carlos?"; Mistos: nessa classe é possível combinar problemas das classes anteriores. Por exemplo, "João tinha 13 carrinhos deu alguns para seu irmão ficando com 8 carrinhos. Depois ganhou 4 carrinhos de seu pai. E, por fim, presenteou seu primo com 4 carrinhos. Quantos carrinhos João deu ao todo? E com quantos carrinhos João ficou no final?" (MENDONÇA et al., 2007, p. 225-226).
\end{abstract}

Vergnaud (2014) também diferencia os problemas de multiplicação e divisão em duas categorias: "Isomorfismo de medidas" e "Produto de medidas". A primeira consiste em uma proporção direta entre duas grandezas (quantidade e custo, por exemplo). A segunda se refere à composição cartesiana de duas grandezas para encontrar uma terceira (como área, volume, conceitos físicos, etc.).

Aprender sobre as quatro operações (adição, subtração, multiplicação e divisão) exige aprender mais do que os cálculos em si. É importante que os alunos entendam o que estão fazendo e construam conceitos envolvidos nas operações e é por este motivo que dialogamos com a "Resolução de Problemas".

Sobre a seleção dos problemas, Stancanelli (2001) nos apresenta os diferentes tipos de problemas: sem solução; com mais de uma solução; com excesso de dados e de lógica. Assim, o professor pode levar os alunos a debaterem e refletirem, ressaltando a necessidade de interpretar e entender uma situação a partir de representações diversas (pictórica, gráfica, escrita, entre outras). A ampliação do repertório docente torna-se importante ao considerarmos que cada turma possui suas demandas, excluindo a visão de que devemos adotar um único método de ensino. É preciso lembrar que a criação de um ambiente favorável ao debate de aprendizagem implica colocar o aluno como o centro do processo, o estimula e incentiva, possibilita uma participação ativa na construção do conhecimento. 
É preciso conhecer e entender cada uma dessas relações existentes na resolução de problemas, afinal estas apresentam níveis diferentes de dificuldade, sendo essencial para o professor que ensina (ensinará) Matemática desenvolver uma prática de construção dos conceitos de modo significativo e que oportunizem processos que se inter-relacionem. Com isso, o pedagogo, deve ter sua ação planejada com diversos problemas de diferentes graus de dificuldade em um conjunto de situações que envolvam os conceitos a serem assimilados. Deve-se priorizar problemas que oportunizem a diversidade de estratégias e que possibilitem ao aluno estender as perspectivas do campo conceitual em questão.

Para Mengali (2011), as discussões mais contemporâneas acerca do ensino e aprendizagem de Matemática afastam a concepção das aulas centradas no professor como transmissor do conhecimento, dão espaço para a comunicação e ao diálogo. Para a autora:

\footnotetext{
Esse ambiente criado para uma participação ativa do aluno tem como principal característica os momentos de comunicação, priorizando e valorizando as falas dos alunos, dando espaço para uma interação verbalizada, à qual eles mesmos não estavam habituados (MENGALI, 2011, p. 76).
}

Portanto, frente aos dados da investigação que desenvolvemos, analisar a cultura escolar e da sala de aula foi de suma importância para a elaboração do projeto de pesquisa, haja vista que a partir disso foi possível intervir de modo a auxiliar não só nos conteúdos, mas também, na promoção do diálogo e na ruptura do ensino tradicional como a única opção. Diante do diálogo com os referenciais apresentados neste tópico, percebe-se que não há um método ideal para ensinar e/ou aprender Matemática, cabendo ao docente buscar referenciais teóricos que amparem a necessidade de cada turma, o que nos fora possibilitado pelo espaço do estágio como eixo catalisador de formação e de pesquisa nos anos iniciais em uma abordagem com a Teoria dos Campos Conceituais, caminho este que optamos seguir.

\section{Metodologia}

A abordagem metodológica adotada se enquadra na perspectiva dos estudos qualitativos em educação por se tratar de uma pesquisa-intervenção, de caráter descritivoanalítico. Lüdke e André (1995, p. 46-50) afirmam que "[...] a pesquisa qualitativa tem o ambiente natural como fonte de dados e o pesquisador como seu principal instrumento, os dados são altamente descritivos (...) a análise dos dados tende a seguir um processo sintético [...]". Neste tipo de metodologia, o pesquisador é instrumento principal da investigação ao ponto que observa, registra e interage com a situação pesquisada. A produção de dados é 
descritiva e interpretativa, ou seja, as informações obtidas são transpostas o mais fielmente possível na comunicação dos resultados.

A pesquisa-intervenção consiste em uma pesquisa participativa de caráter socioanalítico (ROCHA; AGUIAR, 1997). Fávero (2011, p. 49) destaca que a "[...] pesquisa intervenção tomada no sentido da pesquisa que gera transformação e ao mesmo tempo obtém dados do processo subjacente a ela [...]", ou seja, possibilita mudança para os sujeitos participantes e traz conhecimentos relevantes sobre o processo ocorrido.

$\mathrm{Na}$ pesquisa-intervenção, a relação pesquisador/objeto pesquisado é dinâmica e determinará os próprios caminhos da pesquisa, sendo uma produção do grupo envolvido. Pesquisa é, assim, ação, construção, transformação coletiva, análise das forças sócio-históricas e políticas que atuam nas situações e das próprias implicações, inclusive dos referenciais de análise (AGUIAR; ROCHA, 1997, p. 97).

A intervenção se articula à pesquisa para produzir uma relação entre instituição da formação-aplicação de conhecimentos, teoria-prática, sujeito-objeto e assim o fizemos no estágio. Primeiramente, a pesquisadora se inseriu na turma de $3^{\circ}$ ano, realizou observações e, com a interlocução e diálogo com o orientador, baseando-se nas teorias citadas no referencial teórico na seção anterior do presente texto, planejou aulas que pudessem contribuir para a aprendizagem dos alunos. Durante a prática, atuou como mediadora e, por se tratar de um estágio, ao mesmo tempo em que ensinava, estava aprendendo.

Dadas especificidades do estágio, como unidade formativa e reflexiva das interações "com" e "na" escola, este trabalho foi caracterizado como pesquisa-intervenção, pois a futura pedagoga (acadêmica da licenciatura em Pedagogia UFSCar) desenvolveu ações pedagógicas, de cunho interventivo, planejadas para a problematização, diálogo e discussão nas aulas de Matemática nos anos iniciais. Para este fim, recorremos à uma sequência didática e atividades que objetivaram provocar mudanças que gerassem avanços na aprendizagem das crianças e, consecutivamente, avaliar os efeitos da intervenção baseados nas teorias. Em relação ao campo de configuração da prática do estágio, a inserção se deu em um $3^{\circ}$ ano do Ensino Fundamental de uma escola estadual localizada na periferia de São Carlos-SP, que atende os ciclos I e II, sendo o período matutino destinado ao ciclo II e o vespertino ao ciclo I.

Na turma estavam matriculados 33 alunos, no primeiro semestre de 2019, alguns da região rural e outros do próprio bairro. A professora titular estava há, aproximadamente, 10 anos na profissão e, desde o início das observações, se mostrou desmotivada e cansada, porém, em alguns momentos, se apresentava esperançosa e determinada a lutar pela aprendizagem das crianças, principalmente, de três alunos que apresentavam, aparentemente, muita dificuldade e um aluno desatento as explicações que se demonstrava 
indisciplinado. Durante todo o estágio, houve essa instabilidade: em um dia ela chamava à atenção dos alunos e os desestimulava, no outro fazia elogios à sala, porém, ao final, estava um pouco enérgica. Não havia muito diálogo entre alunos e professora.

Considerando esse contexto, desenvolvemos uma sequência didática que consiste em um "[...] conjunto de atividades escolares organizadas, de maneira sistemática, em torno de um gênero textual oral ou escrito" (DOLZ; NOVERRAZ; SCHNEUWLY, 2004, p. 82). Esta sequência foi elaborada em doze aulas baseadas a partir dos objetivos alfanuméricos da Base Nacional Comum Curricular (BRASIL, 2017), isso porque a proposta de trabalho da escola em xeque adotava tal perspectiva no planejamento. Contudo, cumpre salientar que exploramos aspectos para além do observável e que a apreciação crítica em relação às formas de apresentação deste documento foram fundamentais ao processo de ressignificação por nós a todo momento.

O foco da sequência foi nos procedimentos de cálculo - mental e escrito - com números naturais e em problemas envolvendo significados da adição e subtração. Buscamos apresentar diferentes tipos de problemas, como situações-problema não-numéricas ${ }^{2}$, por exemplo.

Neste contexto, priorizamos que as situações propostas estivessem relacionadas ao contexto da turma e da escola, ressignificando os problemas do tipo "padrão" a fim de estabelecer maior significado para os alunos, como verificaremos na próxima seção.

\section{Resultados e discussão}

Para o desenvolvimento da intervenção proposta, foram destinados dois dias da semana, durante 1h00' min. cada intervenção, porém, não ficou determinado um horário fixo para essas aulas. Dessa maneira, eram ministradas quando a professora da classe havia terminado seu conteúdo programado ou após as aulas de Educação Física.

A Tabela 1 exemplifica a lógica de organização, em termos de objetivos, das aulas em que os módulos da sequência foram introduzidos na turma do $3^{\circ}$ ano.

Tabela 1 - Desenvolvimento da sequência didática.

AULA

Aula 1

\section{OBJETIVOS}

Apresentar o tema;

Observar as estratégias de resolução de problemas

utilizadas pelos alunos.

\footnotetext{
${ }^{2}$ Ligadas ao campo da lógica e/ou que apresentavam dados escritos sem a representação numérica visível.
} 


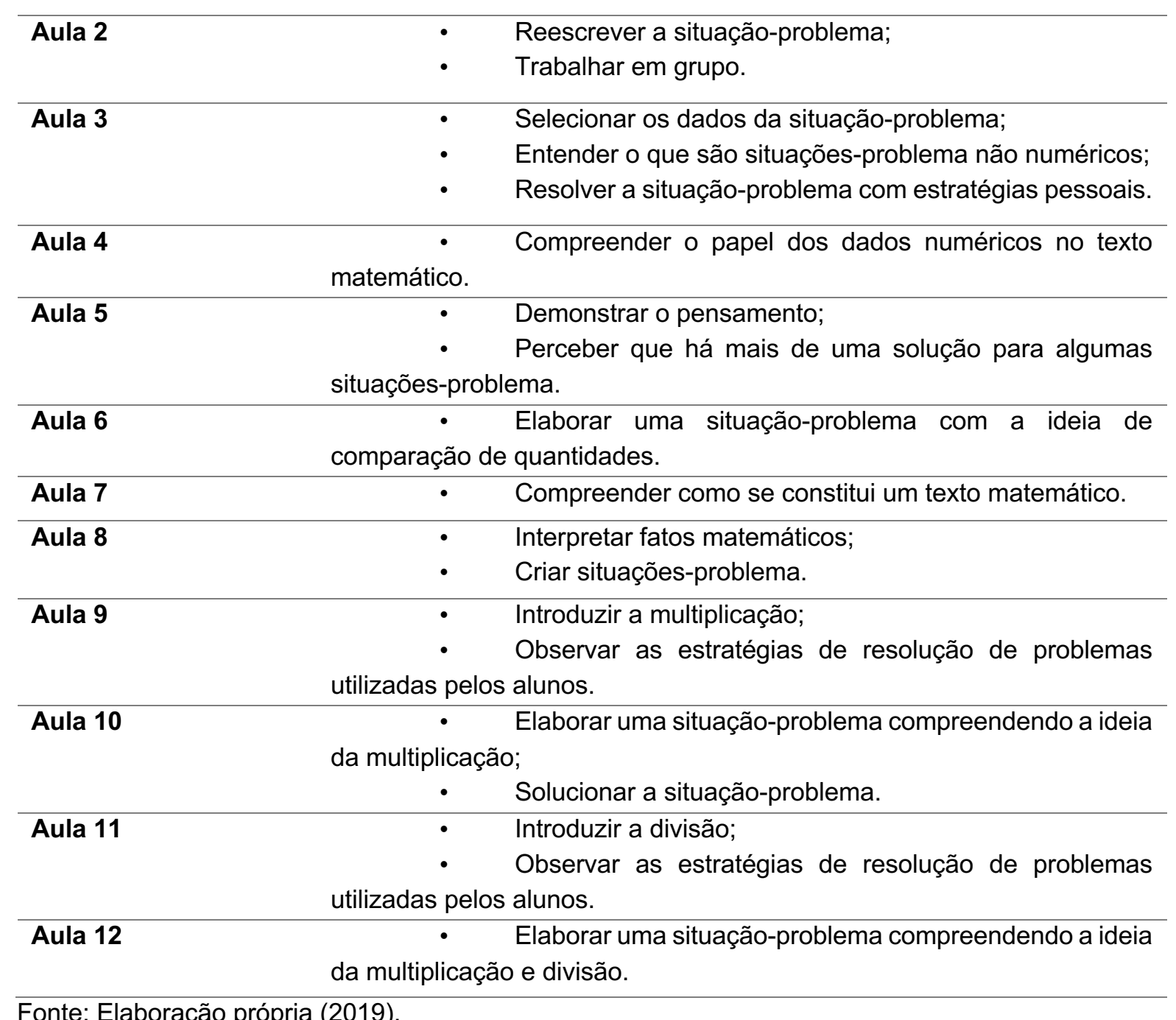

Como todo projeto deve ser flexível, a sequência precisou passar por algumas modificações, se ajustando aos contratempos e adversidades. Algumas aulas foram dadas no mesmo dia, com adaptações por conta do horário.

As três aulas que se destacaram foram a Aula 2, Aula 3 e Aula 12. Portanto, estas serão objeto de apreciação, descrição e análise.

A Aula 2 retomou a situação-problema da Aula 1 e, em grupo, os alunos realizaram a reescrita do problema, modificando a história e os dados. Ao final, cada grupo foi até a lousa apresentar sua situação e os demais grupos resolveram. A situação-problema da Aula 1 era a seguinte:

"Certo dia, João Victor estava no recreio da escola Archimedes brincando de cartinhas com seus amigos Antônio e Bernardo. Então, eles tiveram a ideia de juntar todas as cartinhas. João Victor estava com 24 cartinhas, Antônio estava com 26 e Bernardo com 20. Quantas cartinhas eles tinham no total?". 
Após a leitura, foi solicitado que as crianças propusessem estratégias para a resolução e, em seguida, levantou-se um questionamento: "e se, após a brincadeira, Antônio perdesse 13 cartinhas?".

Os Parâmetros Curriculares Nacionais declaram que, para resolver um problema, é preciso que o aluno:

· elabore um ou vários procedimentos de resolução (como, por exemplo, realizar
simulações, fazer tentativas, formular hipóteses); · compare seus resultados com os
de outros alunos; · valide seus procedimentos (BRASIL, 1997, p. 44).

Após relermos o problema, a mediadora ${ }^{3}$ propôs que cada grupo criasse uma nova situação e, ao final, resolvessem-na. O G2 4 formulou a seguinte situação: "Certo dia, Emilly, Antonio, Nicolly e Kauanni e Bernardo foram ao parque de diversão. Eles pagaram 100 reais, quanto custou cada ingresso?".

A resolução para este problema é ilustrada na Figura 1 dada especificidade da resposta do grupo:

Figura 1 - Resposta das crianças.

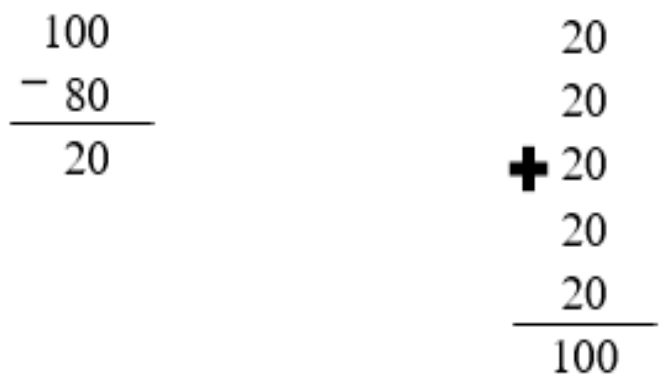

Fonte: Esquema de resposta baseado na experiência (2019).

A mediadora (futura professora) questionou como eles chegaram à tal conclusão e uma das alunas respondeu: "Ué... para dar 100 reais sendo 5 pessoas, só pode ser 20!" Então, perguntou sobre os "100 - 80" e ela disse que era para dar os "20". Na tentativa de problematizar ainda mais a resolução, questionou: "Será que a operação a ser utilizada não deveria ser divisão?" e exemplificou no papel. Ao entenderem, o grupo pediu para refazer e alteraram o final do problema para: "Se cada ingresso custa 20 reais, quanto eles gastaram?"

\footnotetext{
${ }^{3}$ Referimo-nos à pesquisadora como sendo a mediadora. Entendemos por "mediação" o trabalho do professor ao oportunizar a inter-relação entre sujeito (aluno) e objeto de conhecimento (conteúdo).

${ }^{4}$ Sigla para Grupo $2(\mathrm{G} 2)$.
} 
Percebe-se que não houve a compreensão inicial do conceito. Segundo Faxina (2017), os alunos devem ser capazes de desenvolver um algoritmo e entender suas várias dimensões, além de saber aplicá-los nas mais variadas situações.

Ao final do tempo estipulado, cada grupo foi chamado à lousa, a mediadora anotou os dados e todos resolveram as situações-problemas juntos.

Figura 2 - Resolução do grupo 1.

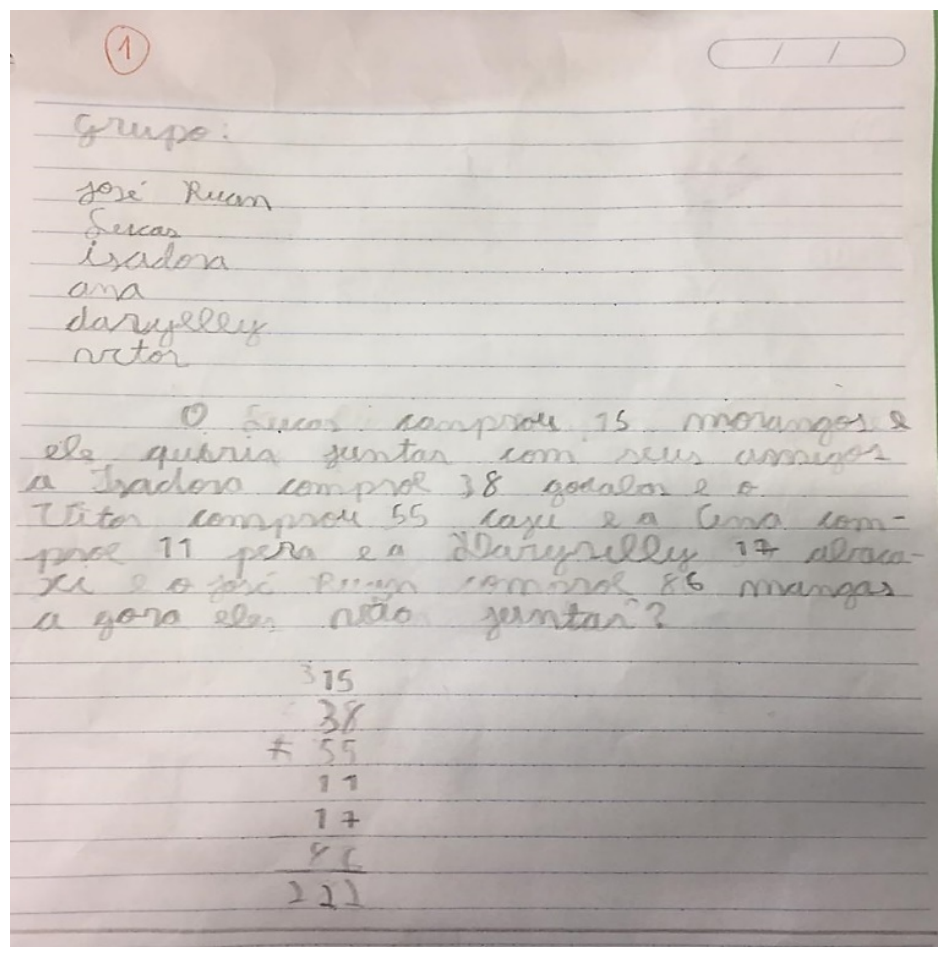

Fonte: Acervo fotográfico dos pesquisadores (2019).

Grupo 1: "O Lucas comprou 15 morangos e ele queria juntar com seus amigos a Isadora comprol 38 goiabas e o Vitor comprou 55 caju e a Ana comprol 11 pera e a Daryelly 17 abacaxi e o José Ruan comprol 86 mangas a gora eles vão juntar" [sic].

Figura 3 - Resolução grupo 2.

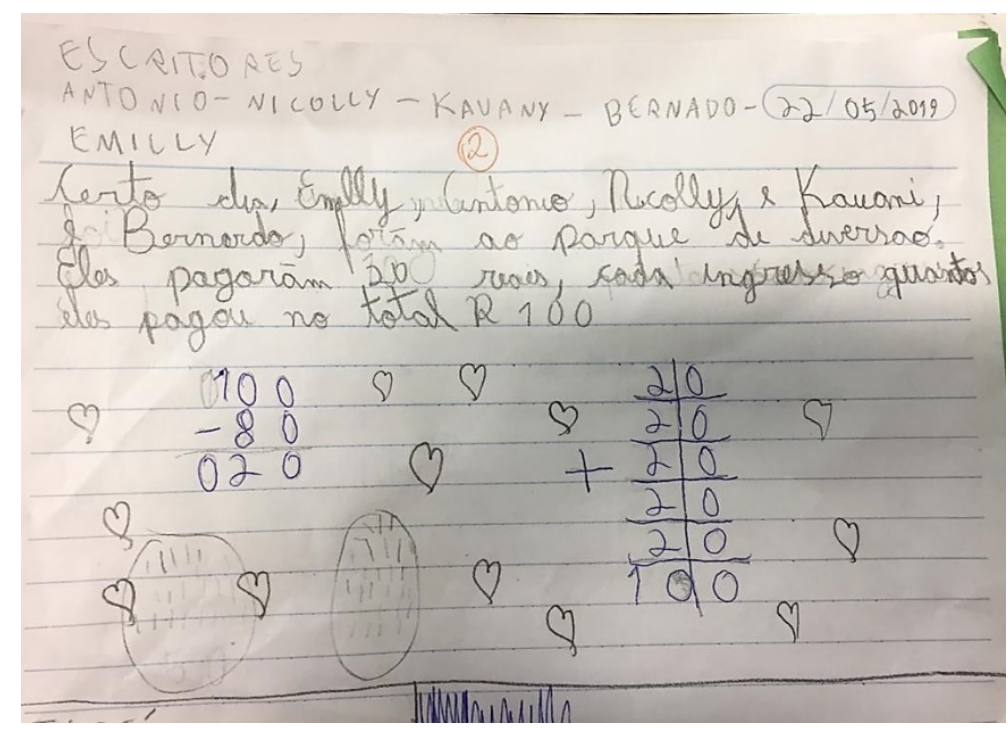

Fonte: Acervo fotográfico dos pesquisadores (2019). 
Grupo 2: "Certo dia, Emilly, Antonio, Nicolly e Kauani e Bernardo, foram ao parque de diversao. Eles pagaram 20 reais, cada ingresso quantos eles pagou no total" [sic].

Figura 4 - Resolução grupo 3.

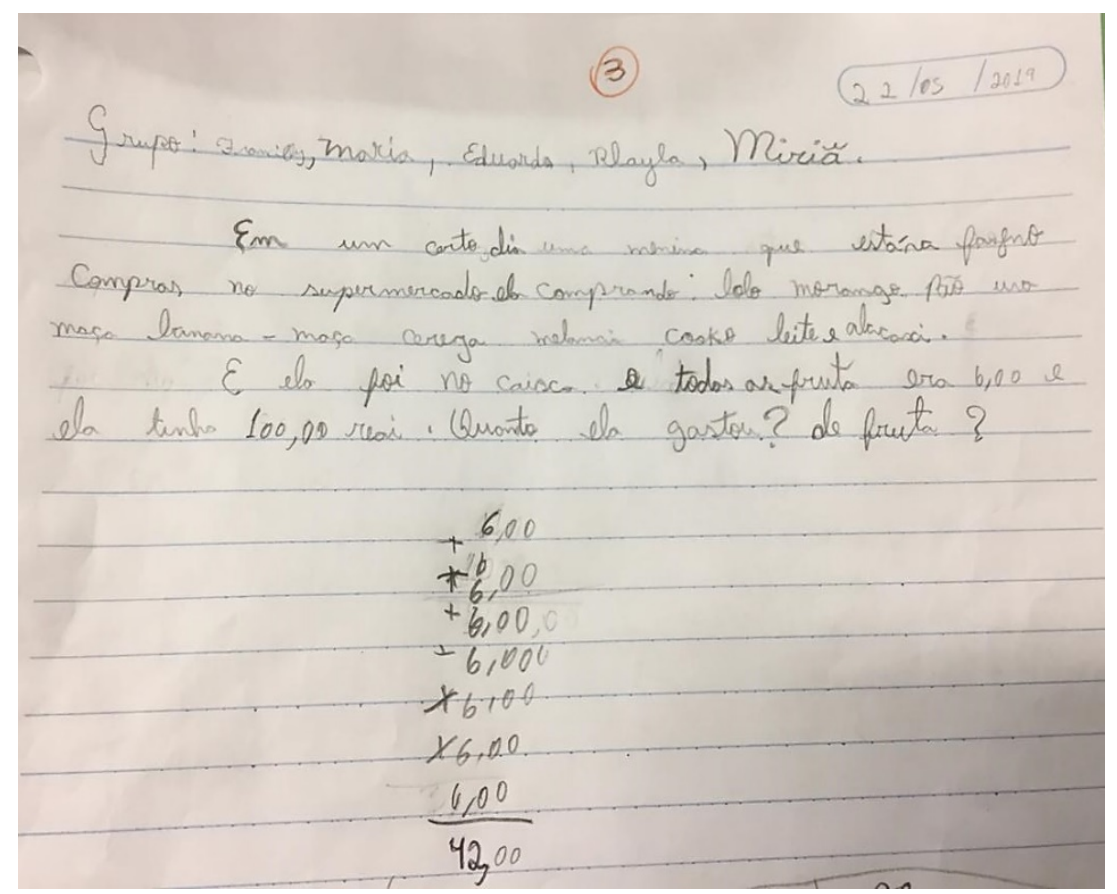

Fonte: Acervo fotográfico dos pesquisadores (2019).

Grupo 3: "Em um certo dia uma menina que estava fazeno compras no supermercado comprando: bolo morando pão uva maça banana-maça cereja melancia cooke leite e abacaxi. E ela foi no caixa e todas as fruta era 6,00 e ela tinha 100,00 reais. Quanto ela gastou? De fruta?" [sic].

Figura 5 - Resolução grupo 4.

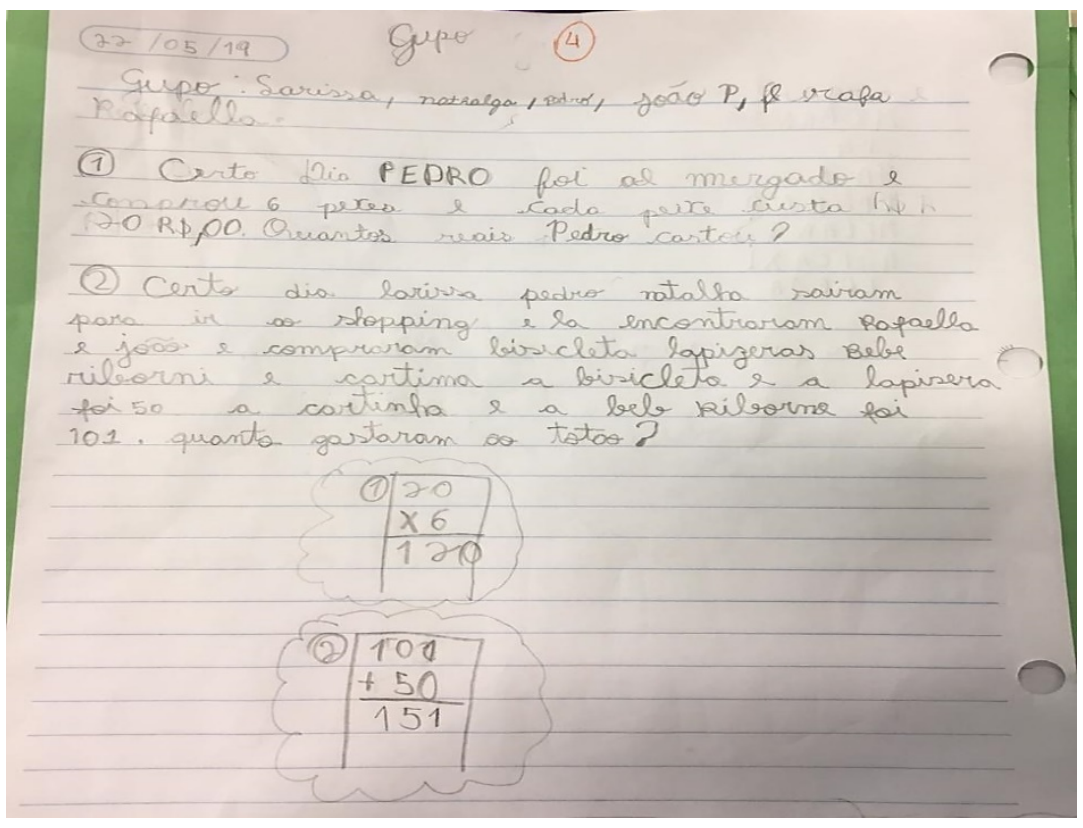

Fonte: Acervo fotográfico dos pesquisadores (2019).

Grupo 4: "Certo dia Pedro foi al mergado e comprou 6 pexes e cada peixe custa $R \$ 20,00$. Quantos reais Pedro castou?" "Certo dia Larissa Pedro 
Natalha saíram para ir ao shopping e la encontraram Rafaella e João e compraram bicicleta lapizeras bebe riborni e cartinha. A bicicleta e a lapiseira foi 50. A cartinha e a bebe riborne foi 101. Quanto gastaram ao totao?" [sic]

Esta atividade proporciona que o aluno mobilize um conjunto de ideias, princípios, procedimentos, técnicas, habilidades e conceitos prévios a fim de criar uma nova situaçãoproblema e tentar solucioná-la, elaborando novos significados em sua estrutura cognitiva (FAXINA, 2017).

A Aula 3 consistiu na apresentação de situações-problema não-numéricas. De acordo com Stancanelli (2001, p. 114), este tipo de problema exige raciocínio dedutivo e promove o desenvolvimento de operações de pensamento "[...] como previsão e checagem, levantamento de hipóteses, busca de suposições, análise e classificação".

A mediadora iniciou com algumas questões norteadoras e, em seguida, expôs a seguinte situação na lousa para resolverem juntos:

"Cinco amigas foram ao Parque Ecológico de São Carlos e levaram seus animais de estimação: um cachorro preto, um cachorro marrom, um coelho, uma tartaruga e um gato. Ana tem medo de cachorros. O bichinho de Maria Eduarda não tem pelos. Emilly tem o mesmo animal de Isadora, mas a cor é marrom. O animal de Kauanni é muito falado pelas crianças na época da Páscoa. Qual é o animal de estimação de cada menina?"

Os alunos conseguiram resolver sem dificuldades e, após 15 minutos, auxiliaram a mediadora a sistematizar os dados pertinentes para solução no quadro. Questionados sobre qual a primeira coisa que conseguimos descobrir, disseram que foi o bichinho de Maria Eduarda, pois não tem pelos, então, só poderia ser a tartaruga. Depois responderam que o animal de Emilly é o cachorro marrom, porque é o mesmo de Isadora e há dois cachorros no enunciado. Em seguida, afirmaram que o de Kauanni é o coelho, pois este é o animal mais falado na Páscoa. Então, disseram que a Sara era a dona gato, uma vez que tem medo de cachorro e a Isadora tem o cachorro preto.

Após a resolução, novas questões foram feitas, como: "é preciso realizar algum cálculo para resolver o problema?", "as informações apresentadas são suficientes para responder a pergunta?". Os estudantes responderam que não foi preciso realizar cálculos e que as informações apresentadas previamente eram suficientes. Dado o contexto propício, a mediadora propôs um desafio aos alunos que, em duplas, deveriam resolver: 


\begin{tabular}{|c|c|}
\hline \multicolumn{2}{|c|}{ "Jéssica, Khalil, Eduardo e Francielly são irmãos. Sabemos que: } \\
\hline a) & Jéssica é a mais velha; \\
\hline b) & Eduardo não é o mais novo; \\
\hline c) & Francielly é mais velha que Khalil e mais nova que Eduardo; e \\
\hline d) & Khalil é mais novo que Jéssica. \\
\hline Você sabe & onder qual a ordem em que nasceram os quatro irmão \\
\hline
\end{tabular}

A maior dificuldade apresentada foi em relação a informação "C". A professora da turma (supervisora do estágio) comentou que a mediadora "confundiu" a cabeça dos alunos. Frente ao exposto, algumas duplas solicitaram ajuda da mediadora, mas outras conseguiram resolver sozinhas. Todos responderam corretamente, a título de ilustração vejamos a Figura 6.

Figura 6 - Resposta do desafio.

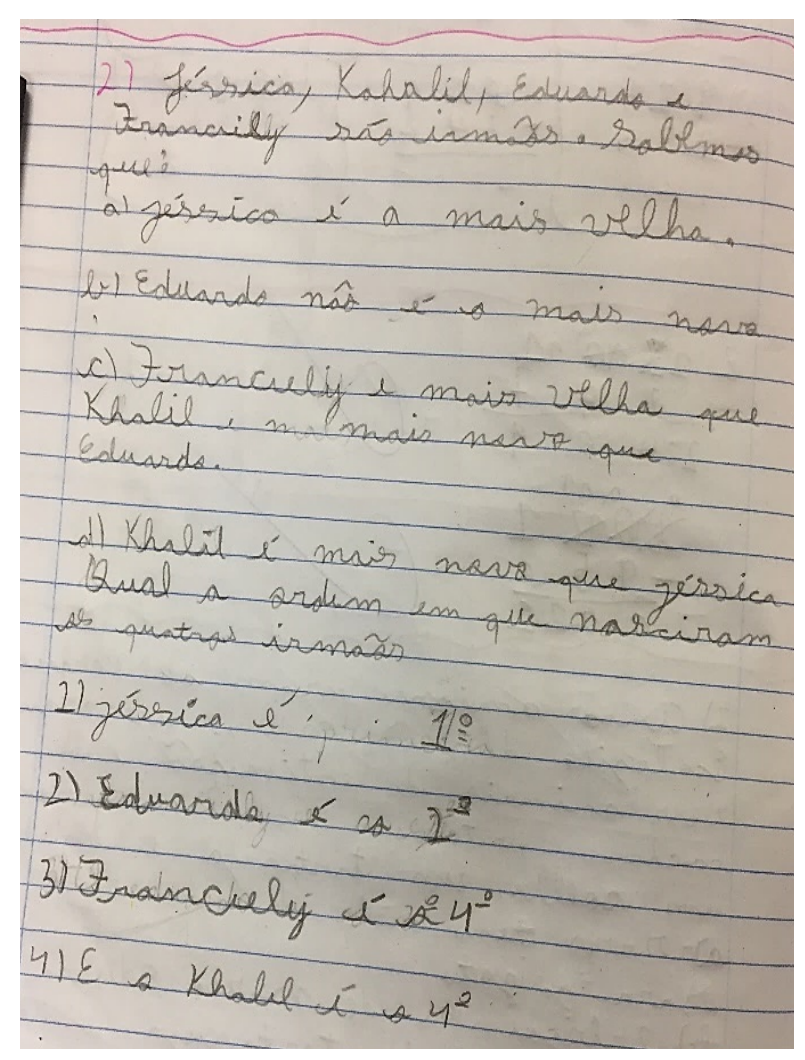

Fonte: Acervo fotográfico dos pesquisadores (2019).

Por fim, a Aula 12 ocorreu também com o trabalho coletivo em que cada grupo deveria estourar um balão que continha em seu interior um número e uma operação. A partir disso, os grupos precisaram elaborar uma situação-problema com a operação sorteada e o resultado necessitaria ser o número, também sorteado. Ao final, as situações foram expostas pelos grupos e os demais ajudaram a corrigir. 
Ao estourarem os balões, os três grupos encontraram-se em um clima de descontração, permitindo que a tarefa fosse feita de forma leve e agradável. Um grupo em especial chamou-nos à atenção. A operação sorteada foi "subtração" e o resultado deveria ser "288". A estratégia utilizada foi a seguinte:

Figura 7 - Estratégia de resolução.

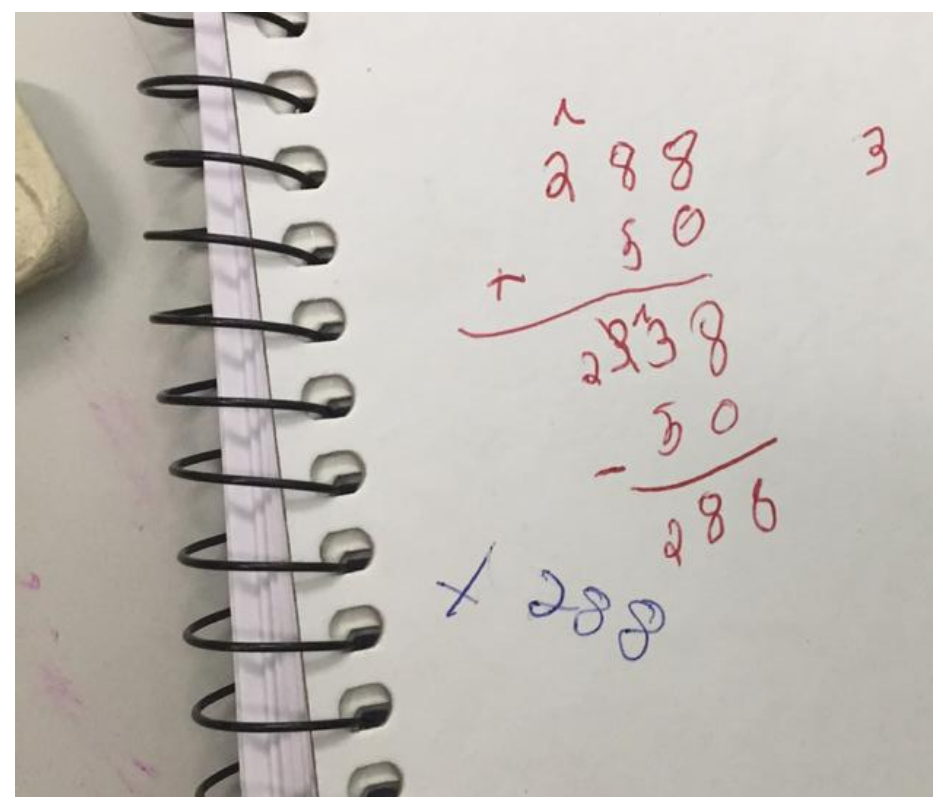

Fonte: Acervo fotográfico dos pesquisadores (2019).

Ao solicitar que explicassem a ideia, uma das alunas falou: "Pensamos em fazer uma prova real. A gente quis usar o "50", então, fizemos "288 + 50" e deu "338", então, vamos fazer uma pergunta que tenha "338 - 50" para dar '288'”.

Neste caso, identificamos um "esquema de ação", definido como "[...] a organização invariante do comportamento para uma classe de situações dada" (VERGNAUD, 1993, p. 2). São nos esquemas que pesquisamos os conhecimentos em ação do aluno, ou seja, "[...] os elementos cognitivos que fazem com que a ação do sujeito seja operatória" (VERGNAUD, 1993, p. 2). Em uma leitura interpretativa dessa questão, concordamos com Vergnaud (1993) que um conceito não pode ser definido, puramente, por sua definição quando o que está em jogo é o ensino e a aprendizagem. Para o autor, é por meio das "[...] situações e dos problemas a resolver que um conceito adquire sentido para a criança" (VERGNAUD, 1993, p. 1).

Percebe-se, então, que as alunas definiram uma estratégia com base em um conhecimento prévio, o da "prova real" e, assim, chegaram a solução do problema proposto. Além disso, era uma situação nova: criar um problema com base na operação e resultados sorteados. Onuchic e Allevato (2001 apud FAXINA, 2017) afirmam que o problema pode ser 
configurado sendo uma situação que não se sabe resolver, mas há interesse e curiosidade em efetuá-lo, fazendo com que o estudante se sinta desafiado a pensar em um meio de resolvê-lo, o que ficou muito evidente na situação problematizada e exposta na Figura 7.

O grupo que saiu sorteado com a multiplicação precisava obter o resultado "30". Uma das integrantes comentou com a mediadora que estavam pensando em todos os números da tabuada que davam "30" e que assim iriam escolher juntos para fazer a situação-problema.

O grupo da adição, que precisava chegar ao resultado "349", pensou em um número inicial (200), depois somaram "100" para obter "300", um dos meninos disse: "Só falta '49' agora" e elaboraram um problema com os três números.

As Figuras 8, 9 e 10 ilustram os resultados dos grupos mencionados.

Figura 8 - Estratégia do enunciado grupo subtração.

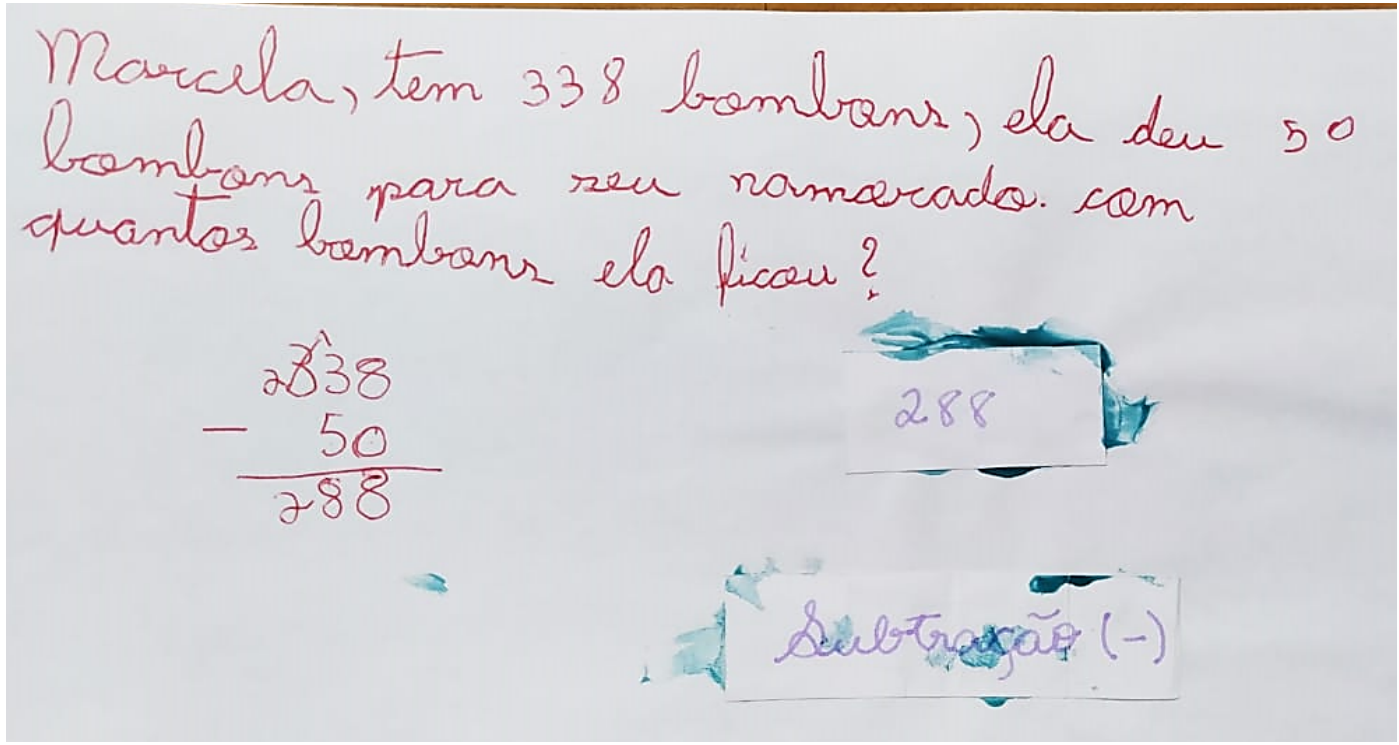

Fonte: Acervo fotográfico dos pesquisadores (2019).

"Marcela, tem 338 bombons, ela deu 50 bombons para seu namorado. Com quantos bombons ela ficou?" [sic].

Figura 9 - Estratégia do enunciado grupo multiplicação.

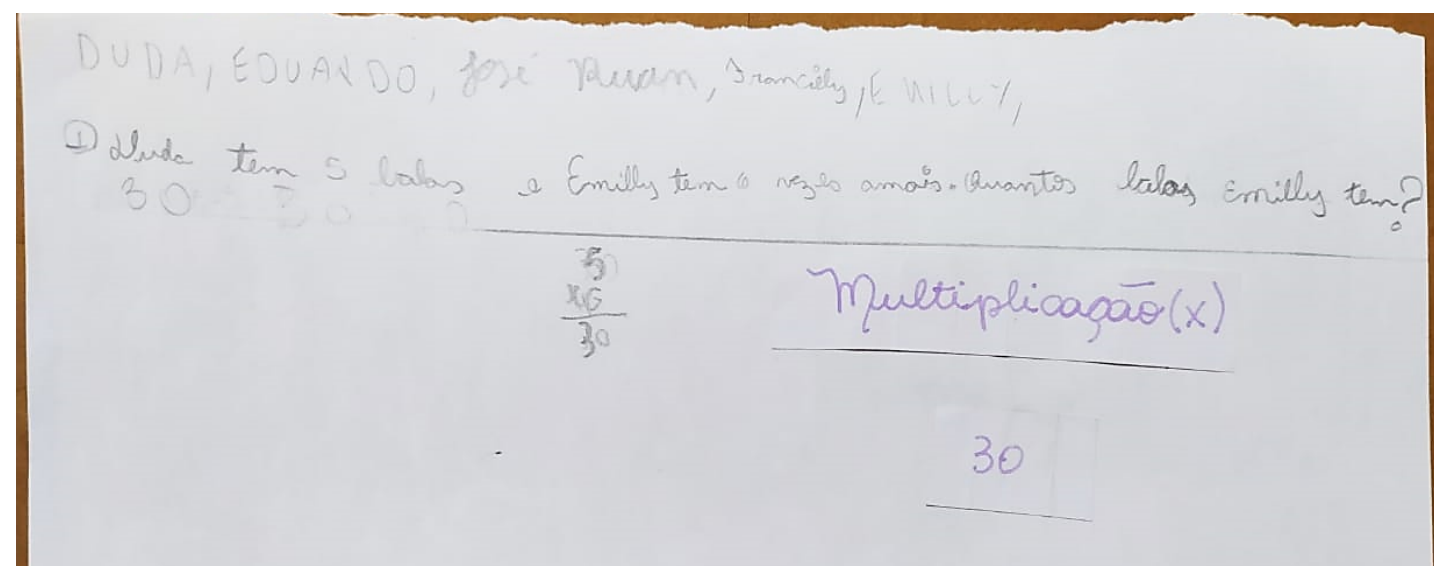

Fonte: Acervo fotográfico dos pesquisadores (2019). 
"Duda tem 5 balas e Emilly tem 6 vezes mais. Quantos balas Emilly tem?" [sic].

Figura 10 - Estratégia enunciado grupo adição.

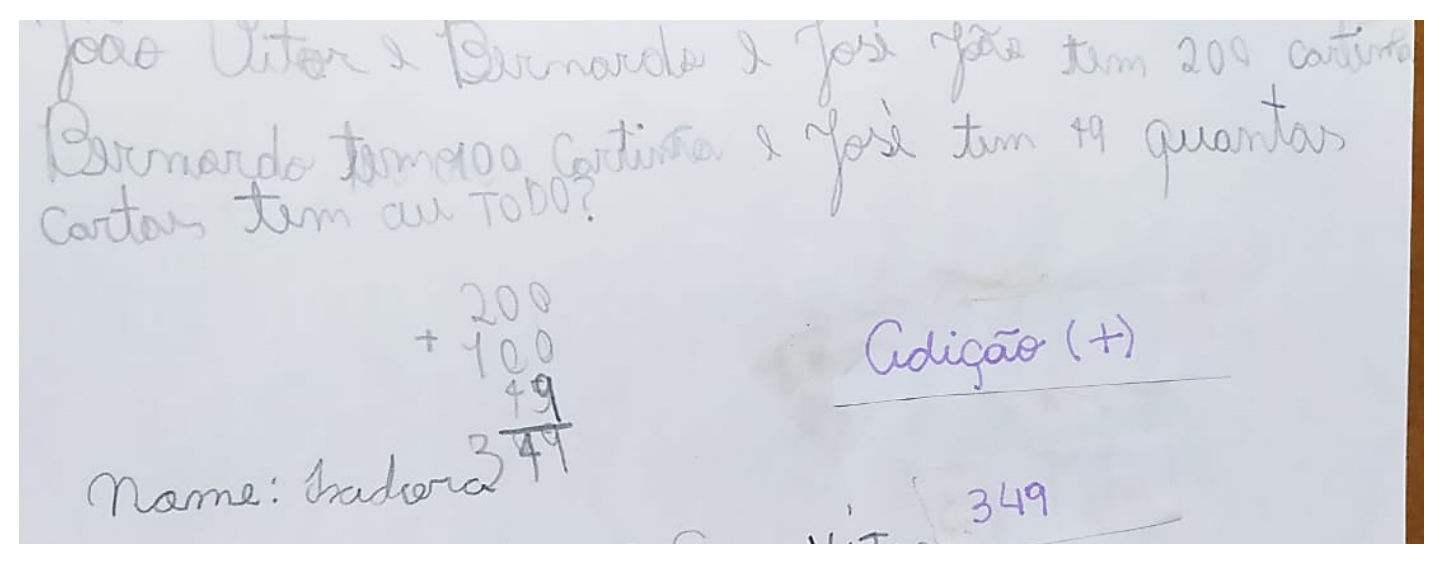

Fonte: Acervo fotográfico dos pesquisadores (2019).

"João Vitor e Bernardo e José João tem 200 cartinhas. Bernardo tem 100 cartinha e José tem 49. Quantas cartar tem au todo?" [sic].

Como vimos, o foco da sequência didática fora nos procedimentos de cálculo - mental e escrito - com números naturais e em problemas envolvendo significados da adição, subtração em uma inter-relação com multiplicação e divisão na perspectiva da Teoria dos Campos Conceituais. Para este fim, buscamos apresentar diferentes tipos de problemas, como situações-problema não-numéricas, por exemplo. Este objetivo foi alcançado, mesmo existindo a necessidade de adaptar a sequência e rever aspectos durante o processo de interação da mediadora (futura professora) com as crianças do $3^{\circ}$ ano.

A partir das atividades e respostas dos alunos, a Teoria dos Campos Conceituais mostrou-se adequada para a resolução dos problemas. Os alunos sentiram-se motivados à participação efetiva no processo ao buscarem soluções, criaram estratégias, principalmente no campo das estruturas aditivas. É possível notar maior insegurança - seja por dificuldade ou por medo de errar - em relação à estrutura multiplicativa, visto que a maioria das crianças buscou respostas na tabuada escrita no caderno.

Segundo Vergnaud (1990, p. 7), "[...] as estruturas aditivas e multiplicativas da aritmética elementar se constroem, por exemplo, num período mais longo que os programas não conhecem [...]", por isso, seria preciso um tempo maior do que apenas doze aulas para oportunizar um maior entendimento e assimilação dos conceitos. Contudo, na experiência em curso do espaço-tempo destinado foi possível perceber o potencial formativo da teoria de Vergnaud à aprendizagem matemática das crianças do $3^{\circ}$ ano.

Durante a realização do estágio foi possível perceber que a resolução de problemas é pouco trabalhada na turma em que intervimos e, quando feita, é de modo descontextualizado e sem significação para os alunos. Trazer tarefas matemáticas 
contextualizadas com o cotidiano da turma e que os envolvessem fez diferença, resultou em maior significação tendo em vista a problematização durante o trabalho pedagógico. Também foi analisado que elas encontram muita dificuldade no momento de solucionar as situaçõesproblema, perguntando sobre qual algoritmo utilizar, por exemplo: "é conta de mais?", "é de menos?"

Isso evidencia a falta de compreensão do problema e a tentativa de solucioná-lo através de uma simples operação, deixando de lado o desenvolvimento de estratégias de raciocínio matemático, demonstra ainda que a prática de "resolver problemas" estava (ou é) pautada em procedimentos de cálculos sem a compreensão dos enunciados matemáticos que compõe o texto escrito de um problema, dados fundamentais para sua compreensão.

Propor que as resoluções fossem feitas utilizando diferentes métodos, desprendendoos das "contas armadas", possibilitou o rompimento da ideia de que só há uma forma de resolver problemas, fazendo-os pensar "fora da caixa". Além disso, sugerir que os próprios alunos criassem seus enunciados matemáticos, oportunizou, ao que os dados da pesquisa indicaram, a compreensão de quais informações são importantes em um texto matemático, acarretando interpretação e adoção de novas estratégias.

Em suma, tais experiências possibilitaram aos alunos do $3^{\circ}$ ano uma aprendizagem significativa e despertou o interesse para a Matemática, que pode ser ensinada e aprendida de modo lúdico e contextualizado. Apresentá-los às aulas dialógicas mostrou que eles podem ser os protagonistas da própria formação, indo além do domínio da técnica do algoritmo e da aplicação direta de propriedades matemáticas. Ler e resolver problemas, nos anos iniciais do Ensino Fundamental, pode ser uma rica e promissora oportunidade de levar as crianças à pensar, elaborar hipóteses, conjecturá-las, testá-las e concluir processos a partir da exploração dos conceitos das estruturas, neste caso, aditivas e multiplicativas.

No campo da formação docente, inserir-se no ambiente da sala de aula contribuiu para que a futura professora utilizasse o estágio como pesquisa (PIMENTA; LIMA, 2006; CARVALHO, 2012), oportunizando o desenvolvimento de postura e habilidades de pesquisadora, bem como a elaboração de sequência didática e a mediação de aulas, dado que permitiu simultaneamente entender e problematizar as situações que acontecem em uma sala de aula. Além disso, pode conhecer, de forma mais situada, como a Educação Matemática está presente na escola, as perspectivas metodológicas mais presentes no contexto do trabalho docente e ainda que a Teoria dos Campos Conceituais de Vergnaud reflete possibilidades de organização do pensamento e da correlação entre a estrutura aditiva e a estrutura multiplicativa. 


\section{Considerações finais}

Ao longo da discussão presente neste trabalho, objetivamos reunir elementos que contribuíssem para repensar o papel do estágio obrigatório na formação do professor ao defendermos sua organicidade como espaço de pesquisa, particularmente no campo da Educação Matemática nos anos iniciais. A partir desta compreensão, o estágio vai muito além de um simples cumprimento de exigências acadêmicas, representa uma oportunidade de aprendizagem e crescimento tanto pessoal quanto profissional. É uma chance que o futuro professor tem de mostrar sua criatividade e começar a construir sua identidade com a carreira docente. Além disso, é um meio de conectar a Universidade e as instituições escolares, principalmente com a realidade da escola pública brasileira, a qual defendemos veementemente.

Ademais, diante da discussão que se fez, o estágio é uma oportunidade de pesquisa na formação de professores e, principalmente, na formação do professor-reflexivo, sendo este o docente que analisa sua prática confrontando-a com as bases teóricas, experiências de outros colegas e perspectivas de outros campos de conhecimento, objetivando seu crescimento profissional. Com isso, o estágio deixa de ser apenas um componente curricular e passa a integrar as áreas de conhecimento do curso.

Sobre a formação do professor que ensina Matemática, consideramos pela nossa experiência que o momento do estágio pode ser aproveitado para aprofundar sua relação com os conteúdos e adquirir corpus teórico-metodológico e conceitual da futura prática profissional, ao se analisar as metodologias e refletir acerca de seus ideais e propostas.

Dado o desenvolvimento de um projeto de intervenção pedagógica em uma turma dos anos iniciais do Ensino Fundamental, é possível afirmar que as experiências foram desafiadoras desde o momento da elaboração da sequência didática até a prática e do planejamento e seu desenvolvimento em sala de aula. A inserção na docência, via estágio, possibilitou à futura pedagoga compreender que o planejamento é flexível e que o contexto proveniente da organização do trabalho pedagógico pelo docente contribui para uma aula interessante e satisfatória, na qual o diálogo e problematização são elementos constitutivos do fazer matemático com as crianças em uma perspectiva dialógica de atuação.

Sobre a Teoria dos Campos Conceituais, podemos inferir que os resultados da produção de significados com as crianças demonstraram-se satisfatórios dado o tempo disponível para o desenvolver da sequência didática explorada. A partir da observação prévia, pôde-se notar quais habilidades precisavam ser fortalecidas como, por exemplo, a leitura e a 
interpretação textual dos enunciados matemáticos, além do desenvolvimento da estruturação do pensamento matemático, de modo a facilitar as estratégias de resolução de problema.

Quando é proposto aos alunos elaborarem situações-problema, fica evidente que elas são, em sua maioria, do tipo composição, ou seja, apresentam duas ou mais partes conhecidas e busca-se saber o todo. Isso nos mostra que, aparentemente, os estudantes têm mais contato com este grupo de problemas, dado que permite fazer a inferência de que a ação dos professores influencia no detrimento de outros tipos de problemas que poderiam facilitar o entendimento e expandir o repertório acerca do campo conceitual aditivo dos educandos.

A partir dessa observação, é notório que há necessidade de maior reflexão sobre o ensino dos conceitos do campo aditivo, principalmente nas relações estabelecidas com o campo conceitual para o estímulo da ampliação do mesmo. Para isso, a Teoria dos Campos Conceituais foi e é uma referência na contribuição do ensino da Matemática, oportunizando o estudo dos conceitos fundamentados em suas relações e conexões com os demais conceitos.

Por fim, a aproximação com a sala de aula e, consequentemente, com a forma como a Educação Matemática é explorada na escola pública trouxe ainda o entendimento de que a formação continuada é essencial para que a prática docente se adapte às diferentes demandas de cada turma e às mudanças sociais. Por fim, podemos concluir que o estágio desempenha um papel fundamental na formação docente, uma vez que a experimentação de metodologias diversas de ensino ressignifica o conhecimento "de" e "sobre" a Matemática, tanto no contexto escolar quanto no fazer docente e isso permite, ao futuro educador, conhecer a realidade do trabalho e construir sua identidade por meio de observações e reflexões permanentes acerca da prática pedagógica.

\section{Referências}

AGUIAR, Kátia Faria; ROCHA, Marisa Lopes. Práticas Universitárias e a Formação Sóciopolítica. Anuário do Laboratório de Subjetividade e Política, n³/4,1997, p. 87-102.

BRASIL, Ministério da Educação. Base Nacional Comum Curricular (BNCC). Educação é a Base. Brasília, MEC/CONSED/UNDIME, 2018. Disponível em:

http://basenacionalcomum.mec.gov.br/images/BNCC El EF 110518 versaofinal site.pdf. Acesso em: 10, jul. 2019.

BRASIL, Ministério da Educação. Parâmetros Curriculares Nacionais: Matemática. Secretaria de Educação Básica, 1997. Disponível em:

http://portal.mec.gov.br/seb/arquivos/pdf/livro03.pdf. Acesso em: 15, nov. 2019. 
BRASIL, Presidência da República. Casa Civil. Subchefia de Assuntos Jurídicos. Decreto $n^{\circ}$ 6.096, de 24 de Abril de 2007. Institui o Programa de Apoio a Planos de Reestruturação e Expansão das Universidades Federais - REUNI. 2007. Disponível em: http://www.planalto.gov.br/ccivil 03/ ato2007-2010/2007/decreto/d6096.htm. Acesso em: 14, jul. 2021.

CARVALHO, Mercedes. Estágio na licenciatura em Matemática: observações nos anos iniciais. Petrópolis: RJ. Editora Vozes. 2012.

CURI, Edda. Formação de professores polivalentes: uma análise de conhecimentos para ensinar Matemática e de crenças que interferem na constituição desses conhecimentos. 2004. 278f. Tese (Doutorado em Educação Matemática) - Pontifícia Universidade Católica de São Paulo - PUC/SP, São Paulo-SP. 2004. Disponível em:

http://www.educadores.diaadia.pr.gov.br/arquivos/File/2010/artigos teses/MATEMATICA/Te se curi.pdf. Acesso em: 13, abr. 2020.

DINIZ-PEREIRA, Júlio. Formação de professores, trabalho docente e suas repercussões na sala de aula. Educação \& Linguagem. ANO 10. № 15. 82-98, JAN.-JUN. 2007. Disponível em: https://www.metodista.br/revistas/revistas-ims/index.php/EL/article/view/158/168.

Acesso em: 14, jul. 2021.

DOLZ, Joaquim; SCHNEUWLY, Bernard. Gêneros e progressão em expressão oral e escrita - elementos para reflexões sobre uma experiência suíça (francófona). In:

SCHNEUWLY, Bernard; DOLZ, Joaquim. e colaboradores. Gêneros orais e escritos na escola. [Tradução e organização: Roxane Rojo e Glaís Sales Cordeiro]. Campinas-SP: Mercado de Letras, 2004.

FÁVERO, Maria Helena. A pesquisa de intervenção na psicologia da educação matemática. Educar em Revista. Curitiba. Editora UFPR. n. Especial 1/2011, p. 47-62, 2011. Disponível em: http://www.scielo.br/pdf/er/nse1/04.pdf. Acesso em: 28, set. 2020.

FAXINA, Josiane. Resolução de problemas e o ensino dos conceitos aritméticos: percepção dos professores dos anos iniciais do ensino fundamental. 2017. 167f. Dissertação (Mestrado Profissional em Docência para a Educação Básica) - Faculdade de Ciências da Universidade Estadual Paulista "Júlio de Mesquita Filho". Bauru-SP, 2017. Disponível em: https://repositorio.unesp.br/handle/11449/150345. Acesso em: 13, out. 2019.

FIORENTINI, Dario; NACARATO, Adair Mendes; FERREIRA, Ana Cristina; LOPES, Celi Spasandin; FREITAS, Maria Teresa Menezes; MISKULIN, Rosana Giaretta Sguerra. Formação de professores que ensinam matemática: um balanço de 25 anos de pesquisa brasileira. Educação em Revista, Belo Horizonte, n. 36, p.137-159, 2002. Disponível em: http://educa.fcc.org.br/pdf/edur/n36/n36a09.pdf. Acesso em: 28, set. 2020.

GATTI, Bernardete Angelina; BARRETO, Elba Siqueira de Sá. (Coord.) Professores do Brasil: impasses e desafios. Relatório de Pesquisa. Fundação Carlos Chagas. Brasília: UNESCO, 2009. Disponível em: https://www.fcc.org.br/fcc/wpcontent/uploads/2019/04/Professores-do-Brasil-impasses-e-desafios.pdf. Acesso em: 15, jun. 2020.

GOMES, Marineide de Oliveira; PIMENTA, Selma Garrido. Unidade teoria e prática e estágios supervisionados na formação de professores polivalentes: indícios de inovação em cursos de pedagogia no estado de São Paulo. In: Cursos de pedagogia: inovações na formação de professores polivalentes [S.I: s.n.], 2019. 
GONÇALVES, Carlos Luiz; PIMENTA, Selma Garrido. Revendo o ensino de 20 Grau: propondo a formação do professor. São Paulo: Cortez, 1990.

JENSKE, Grazielle. A Teoria de Gérard Vergnaud como aporte para a superação da defasagem de aprendizagem de conteúdos básicos da Matemática: um estudo de caso. 2011, 86f. Dissertação (Mestrado em Educação em Ciências e Matemática) - Faculdade de Física da Pontifícia Universidade Católica do Rio Grande do Sul, PUC-RS, Porto Alegre, 2011.

LÜDKE, Marli; ANDRÉ, Menga. Pesquisa em educação: abordagens qualitativas. São Paulo: E.P.U, 1995.

MAGINA, Sandra. Teoria dos Campos Conceituais: contribuições da Psicologia para a prática docente. In: Anais do XVIII Encontro Regional de Professores de Matemática. São Paulo: UNICAMP. Disponível em: http://www.ime.unicamp.br/erpm2005/anais/conf/conf 01.pdf. Acesso em: 1, maio 2020.

MELLO, Simone Portella Teixeira de; LINDNER, Luciana Martins Teixeira. A contribuição dos estágios na formação docente: observações de alunos e professores. In: Anais do IX Seminário de Pesquisa em Educação da Região Sul - ANPED SUL. Caxias do Sul: RS. 29 de Julho a $1^{\circ}$ de Agosto, 2012. p.1-10. Disponível em: http://www.ucs.br/etc/conferencias/index.php/anpedsul/9anpedsul/paper/viewFile/362/978. Acesso em: 3, ago. 2020.

MENDONÇA, Tânia Maria; PINTO, Sandra Maria; CAZORLA, Irene Mauricio; RIBEIRO, Eurivalda. As estruturas aditivas nas séries iniciais do ensino fundamental: um estudo diagnóstico em contextos diferentes. Revista Latinoamericana de Investigación en Matemática Educativa. 2007. 10(2): 219-239. Disponível em: http://www.scielo.org.mx/pdf/relime/v10n2/v10n2a3.pdf. Acesso em: 15, jul. 2020

MENGALI, Brenda Leme da Silva. A cultura da sala de aula numa perspectiva de resolução de problemas: o desafio de ensinar matemática numa sala multisseriada. 2011. 218f. Dissertação (Mestrado em Educação) - Universidade São Francisco - USF, ItatibaSP, 2011. Disponível em:

https://www.usf.edu.br/galeria/getlmage/385/432205416021476.pdf. Acesso em: 15, set. 2019.

PIMENTA, Selma Garrido. O estágio na formação de professores: unidade teoria e prática? 4. ed. São Paulo: Cortez, 2001.

PIMENTA, Selma Garrido; LIMA, Maria Socorro Lucena. Estágio supervisionados e o Programa Institucional de Bolsa de Iniciação à Docência: duas faces da mesma moeda? Revista Brasileira de Educação, v. 24, e240001, 2019. Disponível em: https://www.scielo.br/pdf/rbedu/v24/1809-449X-rbedu-24-e240001.pdf. Acesso em: 09 out. 2020.

PIMENTA, Selva Garrido; LIMA, Maria Socorro Lucena. Estágio e Docência: diferentes concepções. Poíesis Pedagógica, 3(3 e 4), 5-24. 2006. Disponível em: <https://www.revistas.ufg.br/poiesis/article/view/10542>. Acesso em: 08 out. 2020.

POLYA, George. Como resolver problemas (Tradução do original inglês de 1945). Lisboa: Gradiva. 2003. 
POLYA, George. Sobre a resolução de problemas de matemática na high school. In: KRULIK, S, REYS, R. E. A resolução de problemas na matemática escolar. Trad. de Domingues, H. H., Corbo, O. São Paulo: Atual, 1997.

ROCHA, Marisa Lopes; AGUIAR, Katia Faria de. Pesquisa intervenção e a produção de novas análises. Psicologia: Ciência e Profissão, v.23, n. 4, 64-73. Brasília: CFP. 2003. Disponível em: http://pepsic.bvsalud.org/pdf/pcp/v23n4/v23n4a10.pdf. Acesso em: 28, set. 2020.

STANCANELLI, Renata. Conhecendo diferentes tipos de problemas. In: SMOLE, Kátia Stocco; DINIZ, Maria Ignez. (Org.). Ler, escrever e resolver problemas: habilidades básicas para aprender matemática. Porto Alegre: Artmed, 2001. p.103-120.

VERGNAUD, Gérard. A criança, a Matemática e a realidade: problemas do ensino da Matemática na escola elementar. Tradução: Maria Lucia Faria Moro. ed. revisada. Curitiba: Ed. UFPR, 2014.

. La théorie des champs conceptuels. Recherches en Didactique des

Mathématiques, Grenoble, v. 10, n. 23, p. 133-170, 1990. Disponível em: https://hal.archives-ouvertes.fr/cel-01528253/document. Acesso em: 15, ago. 2020.

. Psicologia cognitiva e do desenvolvimento e pesquisas em educação matemática: algumas questões teóricas e metodológicas. Trad. de Weiss, J. Apresentação concedida para o grupo Canadense de Estudos em Educação Matemática na Queen'se University, Kingston, jun.1982.

Teoria dos campos conceituais. In: Anais do $1^{\circ}$ Seminário Internacional de Educação Matemática. Rio de Janeiro. 1993. p.1-26. Disponível em: http://odin.mat.ufrgs.br/usuarios/paula/Teoria do Campo Conceitual G.Vergnaud.pdf . Acesso em: 15, abr. 2020

Agradecimentos

Os autores agradecem a parceria entre a Universidade Federal de São Carlos (UFSCar) e a Diretoria de Ensino local pela parceria Universidade-Escola, via estágio obrigatório, sem a qual não teríamos a experiência e oportunidade de adentrar ao contexto escolar, conhecer a cultura da sala de aula e ainda desenvolver o referido projeto de intervenção pedagógica, o qual culminara na pesquisa de conclusão de curso da primeira autora. 